\title{
Triacetin Enhances Levels of Acrolein, Formaldehyde Hemiacetals, and Acetaldehyde in Electronic Cigarette Aerosols
}

\author{
Shawna Vreeke, David H. Peyton, ${ }^{\circ}$ and Robert M. Strongin*๑ \\ Department of Chemistry, Portland State University, 1719 SW 10th Avenue, Portland, Oregon 97201, United States \\ Supporting Information
}

ABSTRACT: The health effects of inhaled electronic cigarette (ecigarette) flavoring compounds are largely unknown. Earlier reports of their chemical reactivity have been conflicting, with some claiming, for example, that the degradation of flavoring chemicals in e-cigarettes to aldehydes is statistically insignificant. It is thus important to understand how these molecules react to afford enhanced aerosol products. The purpose of the current study was to investigate the origin of formaldehyde, acrolein, and acetaldehyde in e-cigarettes that contain the popular additive, triacetin (TA). By using ${ }^{13} \mathrm{C}$ labeling and a combination of ${ }^{1} \mathrm{H} \mathrm{NMR}$ and ${ }^{13} \mathrm{C} \mathrm{NMR}$, we were able to identify that ester hydrolysis of TA occurs to form acetic acid (HOAc) during aerosolization. The released HOAc acts as a catalyst in the degradation of propylene glycol (PG) and glycerol (GLY), increasing the formation of

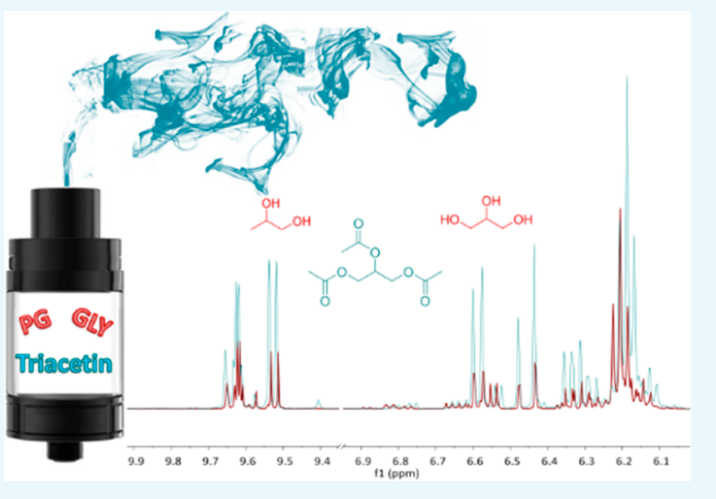
formaldehyde hemiacetals, acrolein, and acetaldehyde. A solution of $10 \%$ TA in 1:1 PG/GLY e-liquid was aerosolized using two different e-cigarettes at two wattages. Each device exhibited a significant increase in aldehyde levels, of up to $185 \%$ compared to the aerosol from a 1:1 PG/GLY e-liquid. In addition, the GLY formaldehyde hemiacetal was more predominant within the presence of HOAc, indicating that GLY may be relatively more prone to degradation from protonation.

\section{INTRODUCTION}

There are approximately 3 million adolescents using electronic cigarettes (e-cigarettes) in the United States. ${ }^{1}$ Moreover, ecigarette usage has been reported to be a major risk factor among youth for traditional cigarette usage. ${ }^{2}$ Flavors are wellknown to be a major contributing factor to the appeal of ecigarettes, ${ }^{3,4}$ particularly among young people. ${ }^{5,6}$ Among US current e-cigarette users, $82 \%$ of young people and $70 \%$ of older adults use flavored e-cigarette liquid (e-liquid). ${ }^{7}$ The Food and Drug Administration (FDA) has yet to pass federal regulation on e-liquid flavoring chemicals. ${ }^{8}$ Research is needed to better understand the identity, levels, reactivity, and inhalation toxicology of specific flavor compounds.

E-liquid is typically composed of a mixture of carrier solvents, nicotine, and flavoring compounds. Many flavorings are listed as generally recognized as safe (GRAS) by the FDA as food additives for ingestion. However, their inhalation toxicity is largely unknown. Despite this, some vaping industry websites claim that e-liquids are safe for inhalation because of their GRAS rating. ${ }^{9,10}$

In addition to the lack of inhalation toxicity data, the chemical reactivity of the flavoring compounds used in ecigarettes has also not been extensively investigated. Previous studies have shown that the aerosolization of flavored e-liquid increases toxic aldehyde production, ${ }^{11}$ oxidative stress, ${ }^{12,13}$ and inflammatory responses. ${ }^{14,15}$ Khlystov and Samburova compared the aldehyde production of flavored e-liquid to that of the aerosol derived from carrier e-liquid [(propylene glycol (PG) and glycerol (GLY)]. They identified a direct relationship between enhanced aldehyde levels and flavor compound concentration. ${ }^{11}$ Others have found that different commercial e-liquid flavoring formulations produced varying aerosol product profiles. ${ }^{16,17}$ However, to date, apart from the determination of sugar-derived furans in e-cigarette aerosols, ${ }^{18}$ there have been no reports focusing on how aerosol products derive from flavoring additives. For example, it is not known if enhanced levels of aldehydes derive directly from the flavoring molecules themselves or if flavorings promote the degradation of other e-liquid components such as the solvents PG/GLY. Herein, we used ${ }^{13} \mathrm{C}$ labeling to unambiguously determine the origin of enhanced aldehyde levels from a relatively common eliquid additive, triacetin (TA), the triester of GLY (i.e., glycerin triacetate, 1,2,3-triacetoxypropane). In addition to e-cigarette products, TA is also found in traditional cigarettes and cigars. ${ }^{19}$

TA is mainly used to enhance the overall flavor of the ecigarette aerosol. It has become popular in the "do-it-yourself" community because of its ability to lessen the "bite". Manufactures are not required to report TA's presence or levels in e-liquids, so its abundance in e-liquids is largely unknown. However, we found three manufacturer websites

Received: April 27, 2018

Accepted: June 13, 2018

Published: July 2, 2018 
that do report TA (Table 1, see also Table S3 in the Supporting Information). Importantly, some companies have also begun to use it as a replacement solvent for PG. ${ }^{21}$

\section{Table 1. TA Reported in Various E-Liquid Flavors}

\begin{tabular}{|c|c|c|c|}
\hline vendor & $\begin{array}{c}\text { flavors which are reported } \\
\text { to contain TA }\end{array}$ & $\begin{array}{l}\text { total flavors } \\
\text { available }\end{array}$ & $\begin{array}{l}\text { frequency } \\
\quad(\%)\end{array}$ \\
\hline $\begin{array}{l}\text { The Flavor } \\
\text { Apprentice }\end{array}$ & 19 & 443 & 4.3 \\
\hline Flavor West & 24 & 338 & 7.1 \\
\hline Simply Flavors & 51 & 150 & 34.0 \\
\hline
\end{tabular}

\section{RESULTS AND DISCUSSION}

Determination of the Aerosol Product Profiles. The two e-cigarette devices EC1 and EC2 were chosen to represent different coil options, namely, a sub-Ohm vertical coil (EC1) and a horizontal coil (EC2). ${ }^{22}$ Each was tested at two battery power settings that were chosen from self-described user preferences (Supporting Information) that were also within the manufacturers' recommended ranges. In order to determine the origin of aldehyde aerosol products from the TAcontaining e-liquid, we synthesized ${ }^{13} \mathrm{C}$-labeled TA from the reaction of GLY and acetic anhydride. Compound 4 (Figure 1)<smiles>CC(=O)O[C@H](C)[C@@H](C)OC(C)=O</smiles>

4

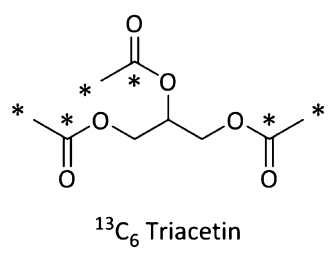

5
Figure 1. Isotopically labeled TA. TA derived from isotopically labeled GLY (4) and from isotopically labeled acetic anhydride (5).

was derived from ${ }^{13} \mathrm{C}$-labeled GLY and compound $\mathbf{5}$ (Figure 1) from ${ }^{13} \mathrm{C}$-labeled acetic anhydride. The use of ${ }^{13} \mathrm{C}$-labeled TA molecules allowed us to determine whether TA forms aldehydes directly via its thermal decomposition (Scheme 1), or if TA plays a different role.

TA has been reported ${ }^{23}$ to degrade under thermal conditions to form acetic acid (HOAc), formaldehyde, acrolein (2), and acetaldehyde (3), as shown in Scheme 1. The IARC (International Agency for Research on Cancer) reports formaldehyde as a known carcinogen and acetaldehyde as a possible carcinogen. ${ }^{24}$ Acrolein is a notorious air pollutant. It has been shown to cause a decrease in respiratory rates and to cause intense eye and respiratory irritation in humans. It has been shown to lead to inflammation, obstruction of the trachea and bronchi, and hemorrhaging in animals. ${ }^{25}$ Previously, 1-3 have been identified in the aerosol of e-cigarettes from the dehydration and oxidation of the e-liquid solvents. ${ }^{26}$

On the basis of the literature precedent, ${ }^{11,23}$ we anticipated an enhanced level of aldehyde byproducts in the aerosol derived from the flavored (i.e., TA-containing) e-liquid as compared to the aerosol from the e-liquid composed of PG/ GLY alone. Indeed, an overlay of the ${ }^{1} \mathrm{H}$ NMR spectra (Figure 2) of the aerosol derived from each type of e-liquid clearly

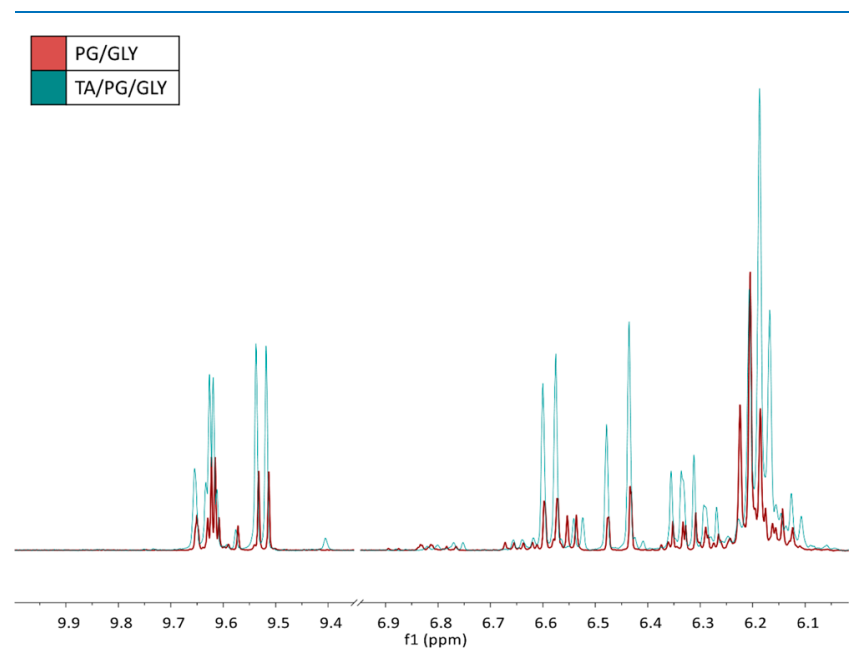

Figure 2. Overlay of the ${ }^{1} \mathrm{H}$ NMR spectra of aerosolized (red) PG/ GLY e-liquid and (blue) 10\% TA/PG/GLY e-liquid. The peaks of interest that increase in height are identified by the doublet at 9.55 $\mathrm{ppm}$ as the aldehyde resonance of acrolein, the multiplet at $6.35 \mathrm{ppm}$ as the trans $\beta$ hydrogen, doublet at $6.47 \mathrm{ppm}$ as the cis $\beta$ hydrogen, and doublet at $6.625 \mathrm{ppm}$ as the $\alpha$ hydrogen resonance of acrolein; the quartet at $9.65 \mathrm{ppm}$ as the aldehyde resonance of acetaldehyde; and last, the overlapping triplets at 6.20 and $6.17 \mathrm{ppm}$ as the hydroxyl resonance of the primary formaldehyde hemiacetals corresponding to PG and GLY, respectively. Chemical peak identification by the addition of authentic standards was performed extensively and published in our previous work. ${ }^{26}$ These spectra were obtained using EC2 at $11 \mathrm{~W}$.

Scheme 1. Two Pathways of TA-Proposed Thermal Degradation ${ }^{a}$

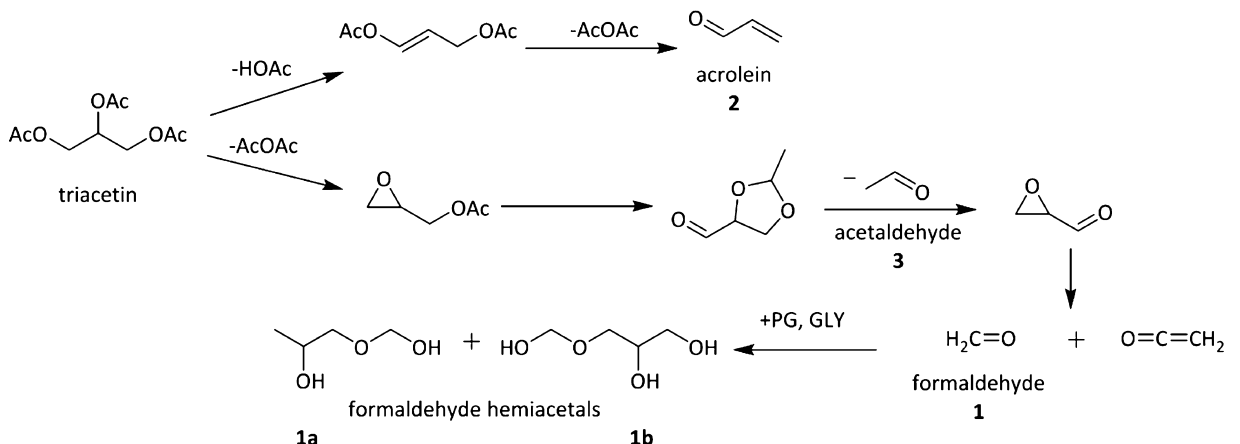

${ }^{a_{\text {TA }}}$ forms acrolein, acetaldehyde, and formaldehyde. In e-cigarettes, formaldehyde further reacts with PG/GLY to form formaldehyde hemiacetals. $^{23,26}$ 
shows that the aerosol derived from the TA/PG/GLY e-liquid contained higher levels of aldehydes $\mathbf{1 a - b}$ (as the formaldehyde hemiacetals), ${ }^{27}$ as well as 2 (acrolein) and 3 (acetaldehyde).

The aerosol levels of $\mathbf{1 a - 3}$ were quantified by ${ }^{1} \mathrm{H}$ NMR, using the internal standard 2,3,5,6-tetrachloro-4-nitrobenzene. Concentrations were normalized by dividing by the mass of eliquid consumed (Supporting Information). The peaks corresponding to compounds $\mathbf{1} \mathbf{a}-\mathbf{b}$ were integrated together because of their overlapping peaks. In EC1 (sub-Ohm), compounds $\mathbf{1} \mathbf{a}-\mathbf{b}$ were the only detectable target products by ${ }^{1} \mathrm{H}$ NMR from aerosolized PG/GLY (Figure 3). However, the

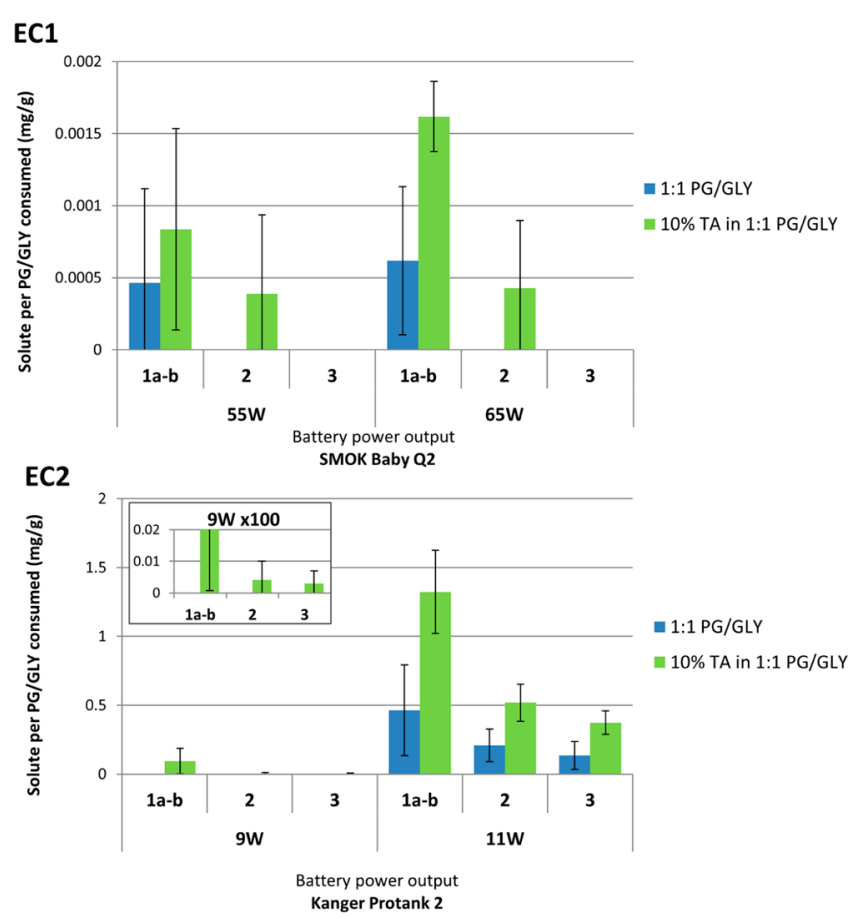

Figure 3. Concentrations of compounds $1 \mathrm{a}-\mathbf{3}$ in the aerosolization of PG/GLY and increased levels with the addition of $10 \%$ TA. The blue bar represents the amount of product $(\mathrm{mg}$ solute/g solution consumed) formed from aerosolized PG/GLY e-liquid. The green bar represents the amount of products formed from aerosolized TA/ PG/GLY e-liquid. The inset displays the results from EC2 at $9 \mathrm{~W}$, expanded by 100 times. 1a, $\mathbf{1 b}, \mathbf{2}$, and 3 represent PG formaldehyde hemiacetal, GLY formaldehyde hemiacetal, acrolein, and acetaldehyde, respectively. Errors bars were calculated by one standard deviation. The enhanced concentration of $\mathbf{1 a}-\mathbf{3}$ was significant under all conditions except in the case of $1 \mathbf{a}-\mathbf{b}$ generated by EC1 at $55 \mathrm{~W}$ (see the Supporting Information).

addition of $10 \%$ TA afforded $80-162 \%$ increases in $1 \mathbf{a}-\mathbf{b}$, as well as a detectable level of $\mathbf{2}$ in the aerosol. The relatively large error bars observed for the EC1 results are due to the fact that the relatively low levels of aldehydes produced were close to the limit of detection of the NMR technique. Although subOhm devices typically produce lower concentrations of aerosol aldehyde products, they typically deliver much greater relative levels of PG and GLY to the user. ${ }^{28}$ The EC2 device thus produced orders of magnitude greater levels of 1a-3 (at 11 $\mathrm{W})$ as compared to EC1 (no TA added). The inclusion of $10 \%$ TA in the EC2 e-liquid led to product increases of 185, 149, and $173 \%$. Using EC2 at $9 \mathrm{~W}$, aerosolized PG/GLY alone afforded no detectable levels of $\mathbf{1 a}-\mathbf{3}$. However, the addition of $10 \%$ TA afforded $\mathbf{1} \mathbf{a}-\mathbf{b}, \mathbf{2}$, and $\mathbf{3}$ in measurable amounts of
$0.09,0.004$, and $0.003 \mathrm{mg} / \mathrm{g}$, respectively. Thus, in the case of each e-cigarette, the e-liquids containing $10 \%$ TA exhibited a clear trend of enhanced relative levels of aldehydes compared to those containing only PG/GLY.

Origin of the Enhanced Product Formation. In order to best inform manufactures, regulatory agencies, and users of potential health risks, it is imperative to determine the sources of increased levels of 1-3. Aerosols derived from PG/GLY containing either $10 \%{ }^{13} \mathrm{C}_{3}$-TA (4) or $10 \%{ }^{13} \mathrm{C}_{6}$-TA (5) eliquids were analyzed by ${ }^{1} \mathrm{H}$ NMR and ${ }^{13} \mathrm{C} N M R$. The ${ }^{13} \mathrm{C}$ NMR of the $10 \%{ }^{13} \mathrm{C}_{6}$-TA (5, acetate-labeled) aerosol displays a prominent peak at $172 \mathrm{ppm}$ corresponding to the carbonyl peak of acetic acid. Importantly, this was the only ${ }^{13} \mathrm{C}$-labeled product observed, and it was not detectable in the $10 \%{ }^{13} \mathrm{C}_{3^{-}}$TA-derived aerosol (4) spectrum. This indicates that ester hydrolysis of TA occurs to form HOAc during aerosolization. The formation of HOAc has the lowest energy barrier of the initial steps in the pyrolysis pathways of TA. ${ }^{23,29}$

Importantly, the degradation of PG and GLY is well-known to be catalyzed by acid and can lead to increased levels of 13. ${ }^{30,31}$ Therefore, we can conclude that TA promotes aldehyde formation in e-cigarettes by producing HOAc that serves as a catalyst to enhance PG and GLY reactivity (Scheme 2). This was confirmed by analyzing the aerosol derived from a control e-liquid consisting of a 1:1 PG/GLY solution containing $0.5 \%$ HOAc, the level of HOAc produced in the experiments using the acetate-labeled TA, 5. Figure 4 reveals that the 1a-3 aerosol spectrum derived from the $\mathrm{HOAc} / \mathrm{PG} / \mathrm{GLY}$ e-liquid exhibits enhanced 1a-3 levels, as is consistent with the findings from the TA/PG/GLY e-liquid (Figure 2).

Finally, we found that the presence of HOAc leads to greater production of the GLY-derived formaldehyde hemiacetal $\mathbf{1} \mathbf{b}$ as compared to the PG formaldehyde hemiacetal 1a (Figure 4). Protonation of GLY has been reported to significantly lower the activation energy of its dehydration from $65-71$ to $20-25$ $\mathrm{kcal} \mathrm{mol}^{-1}$. These results indicate that e-liquids containing TA and higher GLY/PG ratios may be relatively more prone to the enhanced production of formaldehyde and related products.

\section{CONCLUSIONS}

Herein, we have shown that the addition of TA to PG/GLY eliquid affords higher levels of formaldehyde hemiacetals (1ab), acrolein (2), and acetaldehyde (3) by releasing HOAc. This occurs via HOAc formation from TA, followed by acid catalysis of PG/GLY degradation. Although TA may be a direct source of aldehydes, we did not observe this under the conditions herein. One limitation of this study includes not quantifying gaseous formaldehyde because of the method of collection and analysis. However, our previous research has shown that an increase in $\mathbf{1} \mathbf{a}-\mathbf{b}$ concentration is proportional to an increase in gaseous formaldehyde (1) production. ${ }^{32}$ Further related investigations involving additional e-liquid formulations are currently under study in our labs.

\section{METHODS}

Electronic Cigarette Devices. Two devices were used for aerosolization.

EC1. A SMOK Alien $220 \mathrm{~W}$ variable voltage/variable wattage/temperature control (VV/VW/TC) battery was fitted with a SMOK Baby containing a Q2 $0.4 \Omega$ single vertical coil. 
Scheme 2. TA in E-Cigarettes Leads to HOAc Formation and Subsequent Protonation of PG/GLY To Catalyze the Formation of Products Such as $1-3^{a}$

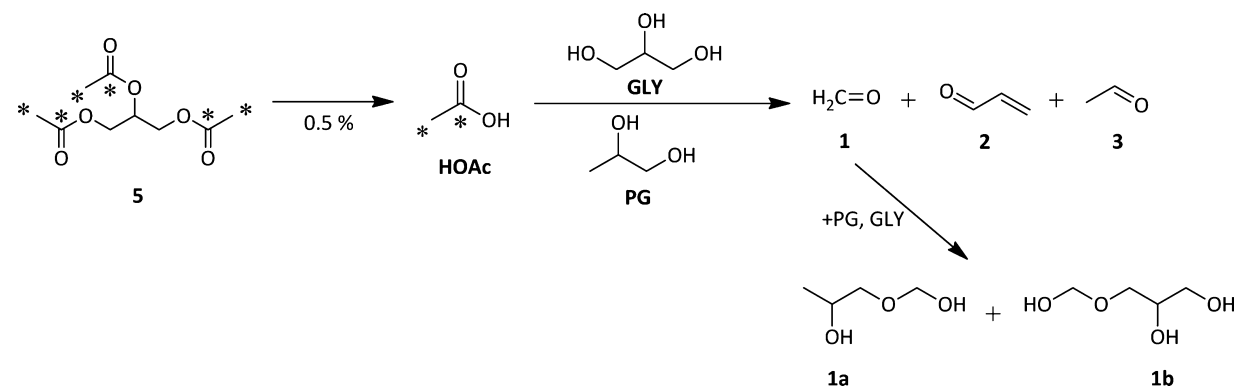

${ }^{a}$ This was confirmed via the use of ${ }^{13} \mathrm{C}$-labeled TA as the predominant pathway observed under the conditions used herein.

\section{PG/GLY}

HOAC/PG/GLY

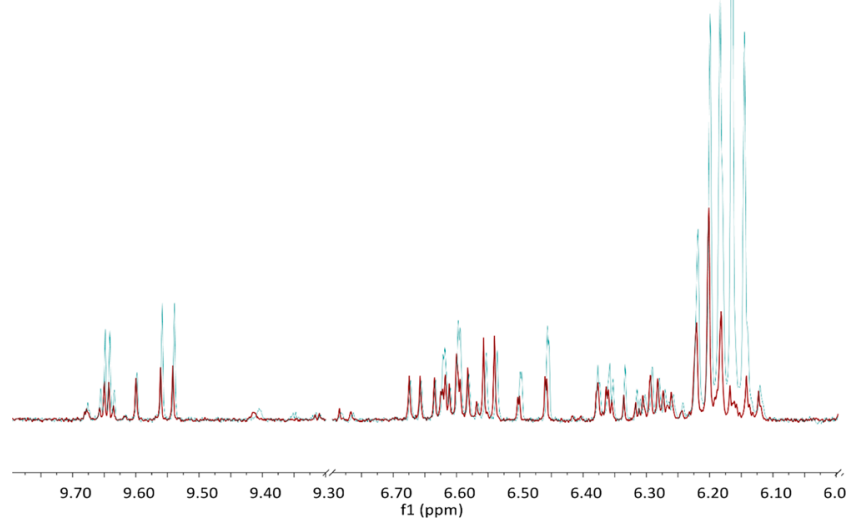

Figure 4. Overlay of ${ }^{1} \mathrm{H}$ NMR spectra of aerosolized (red) PG/GLY e-liquid and (blue) $0.5 \% \mathrm{HOAc} / \mathrm{PG} / \mathrm{GLY}$ e-liquid. The triplet at 6.20 $\mathrm{ppm}$ was identified as 1a. The triplet at 6.17 was identified as $\mathbf{1 b}$. The doublet at $9.55 \mathrm{ppm}$, multiplet at $6.35 \mathrm{ppm}$, doublet at $6.47 \mathrm{ppm}$, and doublet at $6.625 \mathrm{ppm}$ were identified as 2 . The quartet at $9.65 \mathrm{ppm}$ was identified as 3 . In the presence of HOAc there is a visible increase in peaks corresponding to $1 \mathrm{a}-3$. These spectra were obtained using $\mathrm{EC} 2$ at $11 \mathrm{~W}$.

EC2. A SMOK Alien $220 \mathrm{~W} \mathrm{VV} / \mathrm{VW} / \mathrm{TC}$ battery was fitted with a Kanger Protank 2 Clearomizer containing a MT32 2.2 $\Omega$ single horizontal coil.

Synthesis of ${ }^{13} \mathrm{C}$-Labeled TA. ${ }^{13} \mathrm{C}_{3}$-GLY (Sigma-Aldrich) was converted to $\mathrm{C}_{6}{ }^{13} \mathrm{C}_{3} \mathrm{H}_{14} \mathrm{O}_{6}\left({ }^{13} \mathrm{C}_{3}-\mathrm{TA}, 4\right)$ by acetic anhydride and pyridine $\left(25{ }^{\circ} \mathrm{C}, 22 \mathrm{~h}\right)$. Purification was performed by column chromatography, followed by solvent evaporation under reduced pressure to afford the liquid product. Purity was confirmed by ${ }^{1} \mathrm{H}$ NMR and ${ }^{13} \mathrm{C}$ NMR. GLY was converted to $\mathrm{C}_{3}{ }^{13} \mathrm{C}_{6} \mathrm{H}_{14} \mathrm{O}_{6}\left({ }^{13} \mathrm{C}_{6}\right.$-TA, 5) by ${ }^{13} \mathrm{C}_{4}$ acetic anhydride (Cambridge Isotopes) and pyridine $\left(25{ }^{\circ} \mathrm{C}\right.$, $22 \mathrm{~h}$ ). Purification was performed by column chromatography, followed by solvent evaporation under reduced pressure to afford the liquid product. Purity was confirmed by ${ }^{1} \mathrm{H}$ NMR and ${ }^{13} \mathrm{C}$ NMR.

E-Liquid Preparation and Avoidance of Dry Coils and Burnt E-Liquid. Each device was filled with e-liquid to the highest level according to the manufacturers' recommendation.

PG/GLY Solution. A 1:1 ratio (by volume, v/v \%) of PG/ GLY was mixed in-house from ACS-grade PG and GLY. EC1 and EC2 were filled with a mixture of $1.0 \mathrm{~mL}$ PG and $1.0 \mathrm{~mL}$ GLY, respectively.
10\% TA Solution. A 1:1 ratio of $\mathrm{PG} / \mathrm{GLY}(\mathrm{v} / \mathrm{v} \%$ ) was mixed in-house with an addition of $10 \%(\mathrm{v} / \mathrm{v} \%)$ ACS-grade TA.

$10 \%{ }^{13} C_{3}$-TA (4) Solution. A $1: 1$ ratio of PG/GLY (v/v \%) was mixed in-house with an addition of $10 \%(\mathrm{v} / \mathrm{v} \%)$ synthesized 4.

$10 \%{ }^{13} C_{6}-T A(5)$ Solution. A 1:1 ratio of PG/GLY (v/v \%) was mixed in-house with an addition of $10 \%(\mathrm{v} / \mathrm{v} \%)$ synthesized $\mathbf{5}$.

Throughout each vaping session, ample e-liquid was maintained to cover the wicking material. After each session, the e-liquid was replaced with a fresh solution. New coils were also used in each session. Each device was studied at two wattages that were within self-reported user preferences (Supporting Information) as well as within the range of the manufacturers' recommendation.

Collecting the Aerosol. The e-cigarette aerosol consists of liquid particles suspended in the gas phase. ${ }^{33}$ The aerosol produced was passed through a dry cold trap submerged in a dry ice/acetone bath $\left(-76{ }^{\circ} \mathrm{C} \pm 2{ }^{\circ} \mathrm{C}\right)$, followed by an impinger of $0.6 \mathrm{~mL}$ DMSO- $d_{6}$ connected to a $\mathrm{CH}$ Technologies single cigarette smoking machine (SCSMSTEP). Each vaping session consisted of 10 puffs. The SCSM-STEP was set to the CORESTA program, which has a square shape puff profile, a $3 \mathrm{~s}$ puff period, and a $55 \mathrm{~mL}$ puff volume. In this study, the puff interval was set to $1 \mathrm{~min}$ to aid cooling of the heating coils between puffs. EC1 was tested in triplicate at 55 and $65 \mathrm{~W}$. EC2 was tested in triplicate at 9 and $11 \mathrm{~W}$. The aerosolization of ${ }^{13} \mathrm{C}_{3}$-TA (4) e-liquid and ${ }^{13} \mathrm{C}_{6}$-TA (5) e-liquid was each performed once with EC1 at $65 \mathrm{~W}$ and once with EC2 at $11 \mathrm{~W}$. After each puff, DMSO- $d_{6}$ from the impinger was used to collect the aerosols that had condensed inside the cold trap. The dissolved aerosol $(0.425 \mathrm{~mL})$ was placed in a Wilmad $400 \mathrm{MHz}$ NMR tube. An internal standard was added via a $40 \mu \mathrm{L}$ aliquot of a $10.01 \mathrm{mM} \mathrm{2,3,5,6-}$ tetrachloro-4-nitrobenzene solution in DMSO- $d_{6}$.

Analysis by NMR. NMR spectra were obtained with a Bruker $400 \mathrm{MHz}$ AVANCE II+ spectrometer.

${ }^{7} \mathrm{H}$ NMR. ${ }^{1} \mathrm{H}$ NMR spectra were obtained using a $30^{\circ}$ pulse angle, $10 \mathrm{~s}$ relaxation delay, and 256 acquisitions.

${ }^{13} \mathrm{C} \mathrm{NMR}$. Using a $30^{\circ}$ pulse angle, $2 \mathrm{~s}$ relaxation delay, and 2048 acquisitions, ${ }^{13} \mathrm{C}$ NMR spectra were obtained for the sample of (i) $10 \%{ }^{13} \mathrm{C}_{3}$-TA (4) solution, (ii) $10 \%{ }^{13} \mathrm{C}_{6}$-TA (5) solution, and (iii) $10 \%$ TA solution for EC1 at $65 \mathrm{~W}$ and for EC2 at $11 \mathrm{~W}$. Data were processed and analyzed using the software, MNova. 


\section{ASSOCIATED CONTENT}

\section{S Supporting Information}

The Supporting Information is available free of charge on the ACS Publications website at DOI: 10.1021/acsomega.8b00842.

Detailed synthesis procedures, ${ }^{1} \mathrm{H}$ and ${ }^{13} \mathrm{C}$ NMR spectral data, and sample collection data (PDF)

\section{AUTHOR INFORMATION}

\section{Corresponding Author}

*E-mail: strongin@pdx.edu (R.M.S.).

\section{ORCID *}

David H. Peyton: 0000-0001-5828-055X

Robert M. Strongin: 0000-0003-3777-8492

Notes

The authors declare no competing financial interest.

\section{ACKNOWLEDGMENTS}

We thank the NIH and the FDA for their support via award R01ES025257. The content is solely the responsibility of the authors and does not necessarily represent the views of the $\mathrm{NIH}$ or the FDA. We express sincere appreciation to Dr. Jorge Escobedo and Katherine Cook for generosity with their time and knowledge.

\section{REFERENCES}

(1) Singh, T.; Arrazola, R. A.; Corey, C. G.; Husten, C. G.; Neff, L. J.; Homa, D. M.; King, B. A. Tobacco Use Among Middle and High School Students - United States, 2011-2015. MMWR Morb. Mortal. Wkly. Rep. 2016, 65, 361-367.

(2) Bold, K. W.; Kong, G.; Camenga, D. R.; Simon, P.; Cavallo, D. A.; Morean, M. E.; Krishnan-Sarin, S. Trajectories of e-cigarette and conventional cigarette use among youth. Pediatrics 2018, 141, e20171832.

(3) Patel, D.; Davis, K. C.; Cox, S.; Bradfield, B.; King, B. A.; Shafer, P.; Caraballo, R.; Bunnell, R. Reasons for current E -cigarette use among U.S. adults. Prev. Med. 2016, 93, 14-20.

(4) Zare, S.; Nemati, M.; Zheng, Y. A systematic review of consumer preference for e-cigarette attributes: Flavor, nicotine strength, and type. PLoS One 2018, 13, e0194145.

(5) Bold, K. W.; Kong, G.; Cavallo, D. A.; Camenga, D. R.; Krishnan-Sarin, S. Reasons for Trying E-cigarettes and Risk of Continued Use. Pediatrics 2016, 138, e20160895.

(6) Kinouani, S.; Pereira, E.; Tzourio, C. Electronic Cigarette Use in Students and Its Relation with Tobacco-Smoking: A Cross-Sectional Analysis of the i-Share Study. Int. J. Environ. Res. Public Health 2017, $14,1345$.

(7) Berg, C. J. Preferred flavors and reasons for e-cigarette use and discontinued use among never, current, and former smokers. Int. J. Public Health 2016, 61, 225-236.

(8) Vaporizers, e-cigarettes, and other electronic nicotine delivery systems (ENDS). https://www.fda.gov/TobaccoProducts/Labeling/ ProductsIngredientsComponents/ucm456610.htm (accessed Jan 10, 2018).

(9) Info Electronic Cigarettes. The Safety Of E-Liquid, What We Know Now. https://info-electronic-cigarette.com/e-juice/e-liquidsafety (accessed April 12, 2018).

(10) Better Than Food-Grade in Everything You Need to Know About VaporFi E Juices! https://www.vaporfi.com/blog/everythingyou-need-to-know-about-vaporfi-e-juices/ (accessed April 16, 2018).

(11) Khlystov, A.; Samburova, V. Flavoring Compounds Dominate Toxic Aldehyde Production during E-Cigarette Vaping. Environ. Sci. Technol. 2016, 50, 13080-13085.

(12) Lerner, C. A.; Sundar, I. K.; Yao, H.; Gerloff, J.; Ossip, D. J.; McIntosh, S.; Robinson, R.; Rahman, I. Vapors Produced by
Electronic Cigarettes and E-Juices with Flavorings Induce Toxicity, Oxidative Stress, and Inflammatory Response in Lung Epithelial Cells and in Mouse Lung. PLoS One 2015, 10, e0116732.

(13) Muthumalage, T.; Prinz, M.; Ansah, K. O.; Gerloff, J.; Sundar, I. K.; Rahman, I. Inflammatory and Oxidative Responses Induced by Exposure to Commonly Used e-Cigarette Flavoring Chemicals and Flavored e-Liquids without Nicotine. Front. Physiol. 2018, 8, 1130.

(14) Gerloff, J.; Sundar, I. K.; Freter, R.; Sekera, E. R.; Friedman, A. E.; Robinson, R.; Pagano, T.; Rahman, I. Inflammatory Response and Barrier Dysfunction by Different e-Cigarette Flavoring Chemicals Identified by Gas Chromatography-Mass Spectrometry in e-Liquids and e-Vapors on Human Lung Epithelial Cells and Fibroblasts. Appl. In Vitro Toxicol. 2017, 3, 28-40.

(15) Leigh, N. J.; Lawton, R. I.; Hershberger, P. A.; Goniewicz, M. L. Flavourings significantly affect inhalation toxicity of aerosol generated from electronic nicotine delivery systems (ENDS). Tobac. Contr. 2016, 25, ii81-ii87.

(16) Farsalinos, K. E.; Voudris, V. Do flavouring compounds contribute to aldehyde emissions in e-cigarettes? Food Chem. Toxicol. 2018, 115, 212-217.

(17) Eddingsaas, N.; Pagano, T.; Cummings, C.; Rahman, I.; Robinson, R.; Hensel, E. Qualitative Analysis of E-Liquid Emissions as a Function of Flavor Additives Using Two Aerosol Capture Methods. Int. J. Environ. Res. Public Health 2018, 15, 323.

(18) Soussy, S.; EL-Hellani, A.; Baalbaki, R.; Salman, R.; Shihadeh, A.; Saliba, N. A. Detection of 5-hydroxymethylfurfural and furfural in the aerosol of electronic cigarettes. Tobac. Contr. 2016, 25, ii88-ii93.

(19) Farley, S. M.; Schroth, K. R. J.; Grimshaw, V.; Luo, W.; DeGagne, J. L.; Tierney, P. A.; Kim, K.; Pankow, J. F. Flavour chemicals in a sample of non-cigarette tobacco products without explicit flavour names sold in New York City in 2015. Tobac. Contr. 2018, 27, 170-176.

(20) E-cig Express. Comments on MTS Vape Wizard by Flavour Art. http://www.ecigexpress.com/diy-e-liquid/diy-e-liquid-flavors/ flavourart-usa/flavourart-tobacco/mts-vape-wizard-by-flavourart.html (accessed April 12, 2018)

(21) Perfumers Apprentice. Flavors-Non PG. https://shop. perfumersapprentice.com/c-133-flavors-non-pg.aspx (accessed April $12,2018)$.

(22) Vreeke, S.; Korzun, T.; Luo, W.; Jensen, R. P.; Peyton, D. H.; Strongin, R. M. Dihydroxyacetone levels in electronic cigarettes: Wick temperature and toxin formation. Aerosol Sci. Technol. 2018, 52, 370376.

(23) Laino, T.; Tuma, C.; Moor, P.; Martin, E.; Stolz, S.; Curioni, A. Mechanisms of Propylene Glycol and Triacetin Pyrolysis. J. Phys. Chem. A 2012, 116, 4602-4609.

(24) Formaldehyde, 2-Butoxyethanol and 1-tert-Butoxy-2-propanol. IARC Monogr. Eval. Carcinog. Risks Hum. 2006, 88, 39-325.

(25) Faroon, O.; Roney, N.; Taylor, J.; Ashizawa, A.; Lumpkin, M. H.; Plewak, D. J. Acrolein health effects. Toxicol. Ind. Health 2008, 24, 447.

(26) Jensen, R. P.; Strongin, R. M.; Peyton, D. H. Solvent Chemistry in the Electronic Cigarette Reaction Vessel. Sci. Rep. 2017, 7, 42549.

(27) Jensen, R. P.; Luo, W.; Pankow, J. F.; Strongin, R. M.; Peyton, D. H. Hidden Formaldehyde in E-Cigarette Aerosols. N. Engl. J. Med. 2015, 372, 392-394.

(28) Korzun, T.; Lazurko, M.; Munhenzva, I.; Barsanti, K. C.; Huang, Y.; Jensen, R. P.; Escobedo, J. O.; Luo, W.; Peyton, D. H.; Strongin, R. M. E-Cigarette Airflow Rate Modulates Toxicant Profiles and Can Lead to Concerning Levels of Solvent Consumption. ACS Omega 2018, 3, 30-36.

(29) Tuma, C.; Laino, T.; Curioni, A.; Jochnowitz, E.; Stolz, S. Reaction Pathways for the Pyrolysis of Glycerol, Propylene Glycol and Triacetin in the Gas Phase and at Solid Surfaces. Car-Parrinello Molecular Dynamics 2011, Barcelona, Spain, 2011.

(30) Clifton, J. R.; Rossiter, W. J., Jr; Brown, P. W. Degraded aqueous glycol solutions: $\mathrm{pH}$ Values and the Effects of Common Ions on Suppressing pH Decreases. Sol. Energy Mater. 1985, 12, 77-86. 
(31) Nimlos, M. R.; Blanksby, S. J.; Qian, X.; Himmel, M. E.; Johnson, D. K. Mechanisms of Glycerol Dehydration. J. Phys. Chem. A 2006, 110, 6145-6156.

(32) Salamanca, J. C.; Munhenzva, I.; Escobedo, J. O.; Jensen, R. P.; Shaw, A.; Campbell, R.; Luo, W.; Peyton, D. H.; Strongin, R. M. Formaldehyde Hemiacetal Sampling, Recovery, and Quantification from Electronic Cigarette Aerosols. Sci. Rep. 2017, 7, 11044.

(33) Pankow, J. F. Calculating Compound Dependent Gas-Droplet Distributions in Aerosols of Propylene Glycol and Glycerol from Electronic Cigarettes. J. Aerosol Sci. 2017, 107, 9-13. 